The fermentation of

\title{
sugar-beet pulp and sucrose in an artificial rumen, and the effect of linseed oil fatty acids on the fermentation
}

\author{
BY J. W. CZERKAWSKI AND GRACE BRECKENRIDGE \\ Hannah Dairy Research Institute, Ayr
}

(Received 9 May r968-Accepted 26 August 1968)

\begin{abstract}
1. An artificial rumen is described together with associated analytical and sampling procedures.

2. The equipment was used to study the effects of linseed oil fatty acids on the fermentation of sugar-beet pulp and of sucrose by rumen micro-organisms.

3. With sugar-beet pulp the addition of small amounts of linseed oil fatty acids had little effect on total gas production, utilization of sugar and the molar proportions of steam-volatile acids formed, but they strongly inhibited methane production, whereas large amounts of the fatty acids temporarily inhibited the production of gas and utilization of sugar.

4. With sucrose even the smaller amounts of fatty acids had a marked inhibitory effect on the production of gas and utilization of sugar.

5. The technique is assessed critically and the results are discussed in the light of previous experiments in vivo.
\end{abstract}

Many so-called artificial rumens have been described during the last 20 years. These range from the relatively simple all-glass apparatus of Marston (1948) to more refined semi-permeable systems designed to imitate more closely the conditions that exist in vivo (Warner, I956; Dawson, Ward \& Scott, I964). The rumen is analogous to a continuous culture system, and many attempts have been made to utilize this technique for studies of rumen fermentation in vitro (cf. Hobson, 1965 ; Slyter $\&$ Putnam, I 967 ).

The apparatus described here was designed with particular requirements in mind. Only short-term incubations of 6-8 h of diluted rumen contents were contemplated; therefore, it seemed that a provision for the removal of end-products was not strictly necessary. Another requirement was the provision in one apparatus for at least five complete units that could be operated concurrently. These units had to be readily obtainable commercially and easy to assemble. Gas production was one aspect of rumen metabolism that was of considerable importance in our present studies. Therefore, it was decided to use a closed system with provision for both gas and liquid sampling. In view of the short time of the incubations, no special provisions were made for the control of $\mathrm{pH}$ beyond the inclusion of small funnels through which alkali could be added as required.

This apparatus has now been used to investigate the effect of linseed oil fatty acids on the fermentation of sugar-beet pulp and sucrose by the mixed micro-organisms of the rumen. It has been shown that linseed oil fatty acids markedly depress the production of methane by sheep without affecting the digestibility of the basal ration (Czerkawski, Blaxter \& Wainman, I966), and it seemed that further information about the mechanism of the inhibition could be obtained by controlled experiments in vitro. 
Sugar-beet pulp and sucrose were chosen as substrates for two reasons. First, molassed sugar-beet pulp contains a high proportion of readily soluble carbohydrate and sheep can be kept for long periods on a diet that consists mainly of this material and, second, previous experiments with sheep have shown that sugar-beet pulp gives rise to unusually high rates of methane production.

\section{EXPERIMENTAL AND RESULTS}

\section{The apparatus and its operation}

Description. The artificial rumen was of the 'all-glass' type. The gas was made to circulate continuously in a closed system and bubble through the reaction mixture at atmospheric pressure. The complete apparatus was compact and consisted of five units, each comprising a reaction vessel, an expansion chamber, a peristaltic pump and a water manometer (P1. I). The reaction vessels were mounted in a water bath which consisted of a glass fish tank measuring $30 \times 45 \times 90 \mathrm{~cm}$. The water bath was maintained at $39^{\circ}$.

One of the five units will be described in detail and it is represented diagrammatically in Fig. I.

The reaction vessel had a nominal capacity of $700 \mathrm{ml}$ (FR 700F; Quickfit \& Quartz Ltd) and was provided with a flange lid containing five sockets; for clarity only three of these openings are shown in the diagram. One opening was connected to a manometer (M) containing $0.0 \mathrm{I} \mathrm{N}-\mathrm{HCl}$, and provided with a suitable scale. Most connexions were made with screw-cap fittings as shown in the diagram. Another opening was provided with a liquid sampling tube $(\mathrm{L})$. The central opening carried an adaptor (A) with gas inlet and outlet tubes. The remaining two openings, one of which was larger than the other and had a $B_{34}$ joint, were stoppered during some experiments, but could be fitted with additional accessories, such as a feeding hopper or funnel as described below.

The gas was carried by plastic tubing (Portex $3 \mathrm{~mm}$ internal diameter; Portland Plastics Ltd, Hythe, Kent) through a junction (I) to a peristaltic pump (P) (Glen Creston, Stanmore, Middlesex). After passing the expansion vessel (E) and the gas sampling port $(G)$ it re-entered the gas space of the reaction vessel through the reaction mixture. There was no provision for mechanical stirring: this was done by the bubbling of the gas. The peristaltic pumps were provided with good-quality red rubber tubing ( $8 \mathrm{~mm}$ internal diameter, $2 \cdot 0 \mathrm{~mm}$ wall thickness). This tubing had to be replaced more frequently than silicone rubber tubing, but silicone rubber could not be used because of the relatively large amount of oxygen that diffuses through it. When determined under the conditions used in these experiments, the diffusion of oxygen through silicone rubber was ten times greater than the diffusion through ordinary red rubber of equal thickness. The life of the rubber tubes could be prolonged by a coating of silicone grease. Each of the expansion vessels was constructed of Perspex. The piston could be moved up or down by turning the knurled nut (N). The dimensions were such that when the piston was moved $\mathrm{r} \mathrm{cm}$ the volume of the gas space was changed by about $60 \mathrm{ml}$ (the total volume of the manometer). The gas 
sampling port was a $\mathrm{T}$-adaptor with a screw-cap fitting. The side-arm was closed with a silicone rubber septum.

Operation. Each of the vessels was partly filled with $200 \mathrm{ml}$ of artificial saliva (McDougall, 1948) and 200 or $300 \mathrm{ml}$ of water and placed in the water bath. During many of the experiments, the saliva also contained $\mathrm{I} \cdot 5 \mathrm{~g}$ sucrose and $0.2 \mathrm{~g}$ of $\left(\mathrm{NH}_{4}\right)_{2} \mathrm{CO}_{3}$,

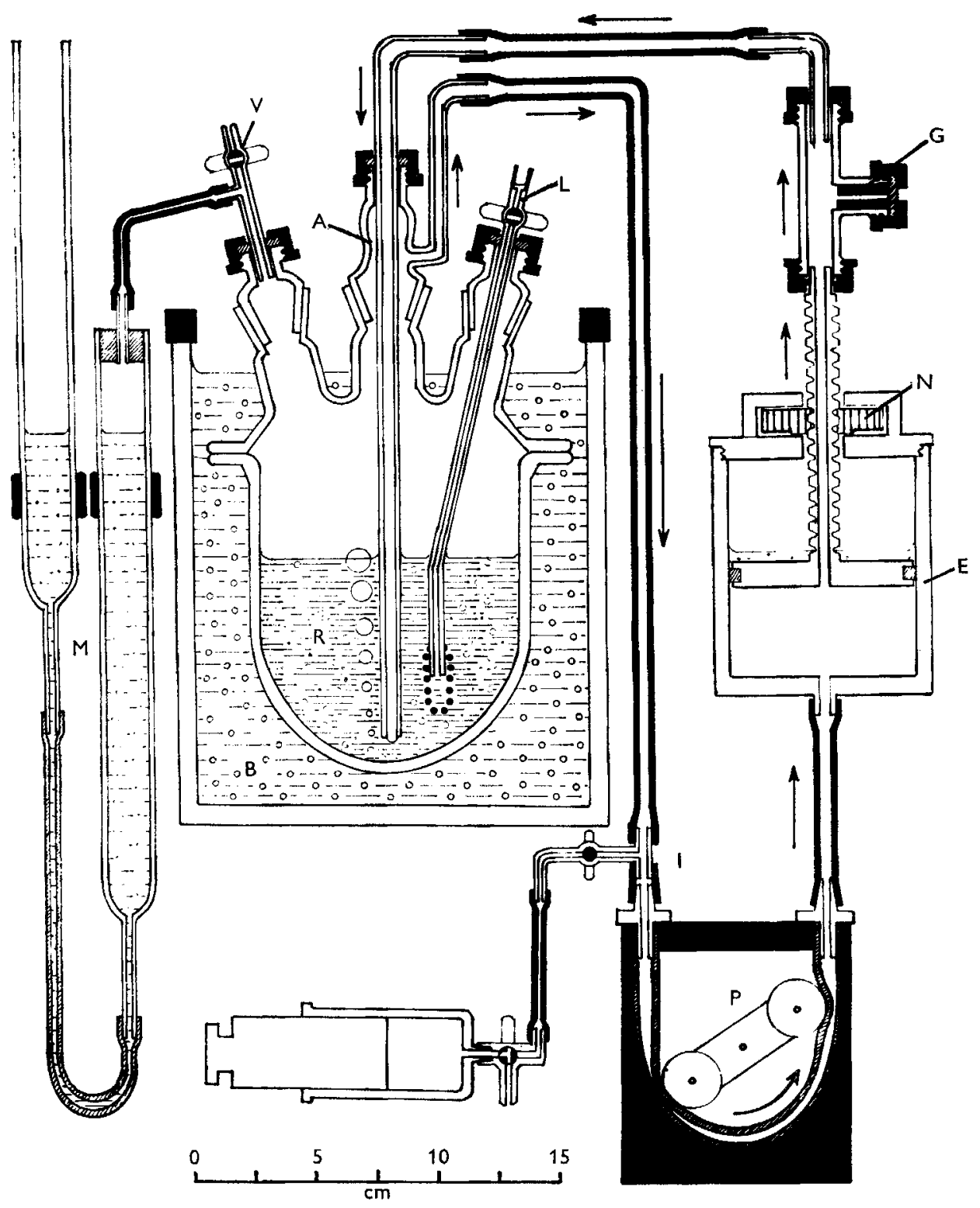

Fig. I. Diagrammatic representation of the artificial rumen; only one complete unit is shown. $A$, adaptor for gas inlet and outlet; $B$, water bath; E, expansion chamber; $G$, gas sampling port; $I$, junction for infusion of gas; $L$, liquid sampling port; $M$, manometers; $N$, nut for adjusting the volume of expansion chamber; $P$, peristaltic pump; $R$, reaction mixture; $V$, vent. 
but these could be added in small volumes of water at any time during the incubation. The supply of the gas to be used (nominally $5 \% \mathrm{CO}_{2}$ in $\mathrm{N}_{2}$ ) was connected to the liquid sampling ports (L, Fig. $\mathrm{r}$ ) and the taps (V) opened. After vigorous gassing for about 2-3 min, the pumps were started, and the expansion vessels adjusted so that the pistons were as low as possible. The residual air was removed from the dead spaces of the lids by momentarily lifting out the appropriate fittings during gassing. Finally, the manometers were moved up and down several times and brought up to their highest point. The gas supply was then turned off and the vents (V) closed.

Analyses showed that, after a total gassing of $10 \mathrm{~min}$ following the above procedure, the $\mathrm{O}_{2}$ content of the gaseous phase in each of the vessels was less than $0.2 \%(\mathrm{v} / \mathrm{v})$. After suitable equilibration and after analysis of the gas samples, the vessels were inoculated with rumen liquor. The latter (usually $100 \mathrm{ml}$ ) was injected with a syringe through the liquid sampling ports (L). The excess gas was allowed to escape through the vent, which was then closed.

The increase in the volume of gas that occurred during incubation was measured at 10-30 min intervals by lowering the moving arm of the manometer until the levels were equal in both arms. When one of the manometers was filled to capacity with gas, the fluid level was brought up again by adjustments in the expansion vessel. In this way it was possible to measure reasonably accurately (to the nearest $0.25 \mathrm{ml}$ ) a total volume increase of about $400 \mathrm{ml}$ using manometers of only $60 \mathrm{ml}$ capacity.

Sampling procedure. Samples of fluid were withdrawn with $20 \mathrm{ml}$ syringes provided with silicone rubber collars that fitted tightly into the sampling ports. In certain experiments the samples withdrawn (ro $\mathrm{ml}$ ) were replaced by injection of an equal volume of fluid from a donor vessel. It is not strictly necessary to replace the fluid removed, but if it is not replaced the manometers have to be reset and suitable corrections have to be made. The actual volume taken was usually ro ml, but initially the $20 \mathrm{ml}$ syringe was filled and emptied several times to ensure that a representative sample was obtained.

The gas samples were small $(5 \mathrm{ml})$, and were taken by first injecting $5 \mathrm{ml}$ of $5 \%$ $\mathrm{CO}_{2}$ in $\mathrm{N}_{2}$ from gas-tight syringes, followed by withdrawal of the sample into the syringe.

Experimental arrangements and additional apparatus. In most experiments four or five units of the type that has been described were used for doing replicate incubations; the sixth unit contained water instead of the reaction mixture and air as the gas phase, but in all other respects the sixth unit was identical with the four or five experimental units and it served as a thermobarometer. Thus, corrections could be made for small variations in temperature and atmospheric pressure.

In some experiments it was necessary to add gases to the gaseous phase during the incubation. The gases were injected by means of an apparatus obtained from Palmer (CFP, Brixton, London). In this apparatus up to three syringes could deliver a maximum of $8-21 \mathrm{ml}$ during an interval that could be varied from $\mathrm{I}$ to $50 \mathrm{~min}$.

Provision was made for the addition of solid substrate to the incubation mixture under anaerobic conditions by using food hoppers. The construction of one such food hopper is shown in Fig. 2. The screw-cap adaptor (A) (Quickfit \& Quartz Ltd) was 
provided with a tightly fitting vessel made of an old polyethylene container $(\mathrm{P})$ that originally contained a BDH standard solution. The glass rod (G) terminated in a rounded trap, also made of polyethylene ( $T$ ). To charge the food hopper, the complete unit was removed from the reaction vessel, turned upside down and the glass rod was pushed up until the collar (C) was near the open end of the vessel. The substrate was

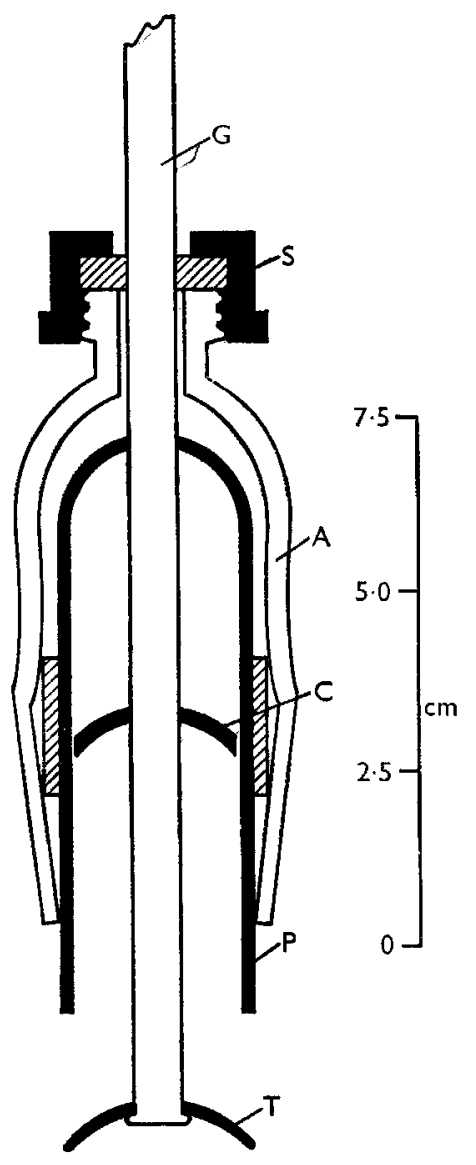

Fig. 2. Diagrammatic representation of the food hopper. A, adaptor; $C$, polyethylene collar; $\mathrm{G}$, glass rod; $\mathrm{P}$, polyethylene container; $\mathrm{S}$, screw-cap; $\mathrm{T}$, trap.

added and the glass rod was withdrawn gradually. It was possible in this way to put $5^{-6} \mathrm{~g}$ of ground food into the hopper. Finally, the rod was drawn back so that the vessel was effectively closed by the trap, and the unit was fitted into the apparatus. When required, the contents of the hopper could be discharged into the vessel by pushing the glass rod down. Moreover, by fitting two or more collars it was possible to add the food in discrete amounts at different times. 


\section{Methods and materials}

Gas analysis. Gas composition was determined chromatographically as described by Czerkawski \& Clapperton (1968). The initial volume of the total circulating gas and the increases in this volume at any time were known and, therefore, it was possible to calculate the increase in volume of any given component. On the other hand, if it is assumed that nitrogen is neither produced nor utilized during the incubation, and that its concentration is known, then it is not necessary to know the initial volume of the gas space. If $V$ is the increase in the total volume of gas, $X_{o}$ and $X_{t}$ are the initial and final concentrations of a particular component in the gas space $(\%, v / v)$, and $Y_{o}$ and $Y_{t}$ are the initial and final concentrations of nitrogen $(\%, v / v)$, the amount of the particular component formed is given by:

$$
\frac{V}{\mathrm{IOO}}\left(\frac{Y_{o} X_{t}-Y_{t} X_{o}}{Y_{o}-}\right)
$$

When, as often happens, the concentration of the component at the start is negligible, the amount formed becomes:

$$
\frac{V}{100} \times \frac{Y_{0} X_{t}}{Y_{0}-Y_{t}}
$$

Alternatively, when the initial volume $\left(V_{o}\right)$ of the gas is known accurately, the volume of the component formed is given by the expression

$$
\frac{V_{o} . Y_{o}}{100}\left[\frac{X_{t}}{Y_{t}}-\frac{X_{o}}{Y_{o}}\right]
$$

and when the initial concentration is negligible, by

$$
\frac{V_{o} \cdot Y_{o} \cdot X_{t}}{100 Y_{t}}
$$

The error incurred in ignoring the volume of gas samples in the present experiments was less than $\mathrm{x} \%$ of any given gas formed and was ignored, but it is easy to correct for this when absolute accuracy is required.

Analysis of liquid samples. The samples were transferred to beakers and the $\mathrm{pH}$ was measured at once. Most of the analyses were carried out as described by Czerkawski (I967). Total sugar was determined by the method of Smith (1956), and the total steam-volatile acids by the method of Conway ( 1962 ).

The concentrations of acetic, propionic and butyric acids were determined as follows. The titrated distillates from Conway units were dried and redissolved in $0.1-0.2 \mathrm{ml}$ water in small tubes. Enough anhydrous $\mathrm{NaHSO}_{4}-\mathrm{Na}_{2} \mathrm{SO}_{4}(\mathrm{I}: \mathrm{I}, \mathrm{W} / \mathrm{W})$ was added to absorb all the fluid (about $0.5 \mathrm{~g}$ ), and the resulting solid was shaken with $0.5 \mathrm{ml}$ of dry, peroxide-free diethyl ether. The ether was decanted and the extraction repeated twice more with $0.3 \mathrm{ml}$ ether. The extracts were pooled, and $0.5 \mu 1$ was injected on a column of polyethylene glycol adipate on chromosorb W in a Pye Argon Gas Liquid Chromatograph. At $120^{\circ}$ and with an argon flow of $20 \mathrm{ml} / \mathrm{min}$ the separa- 
tion of the various components was good. The detector voltage was I $500 \mathrm{~V}$. Some of the samples were analysed by the technique of James \& Martin (1952), and the agreement between the two methods was satisfactory. However, the response of various components was different with the $\beta$-ionization detector of the Pye Argon apparatus, and the instrument had to be calibrated with mixtures of known concentrations of steam-volatile acids.

Source of rumen liquor. Two sheep, each with a rumen fistula, were given a constant ration of $500 \mathrm{~g}$ sugar-beet pulp (at $09.00 \mathrm{~h}$ ) and $500 \mathrm{~g}$ hay (at $\mathrm{I} 6.00 \mathrm{~h}$ ). Samples of rumen contents were withdrawn by suction through a device described by Alexander \& McGowan (1966) into brown jars (600-800 ml) through four layers of muslin tied loosely at the inlet to the jar. The samples were taken before the morning feed and brought to the laboratory in completely filled jars fitted with Bunsen valves. They were kept at $39^{\circ}$ and stirred with a gentle stream of $5 \% \mathrm{CO}_{2}$ in $\mathrm{N}_{2}$ until required for inoculation between 0.5 and $\mathrm{I} h$ after collection.

\section{Fermentation of sugar-beet pulp}

In this series of experiments each vessel contained $200 \mathrm{ml}$ artificial saliva, $300 \mathrm{ml}$ water and $100 \mathrm{ml}$ of strained rumen liquor, except in one vessel where the rumen liquor was replaced by water. The substrate, finely ground molassed sugar-beet pulp (5 g), was added at a predetermined time from the hoppers. In two vessels emulsions $(5 \mathrm{ml})$ of linseed oil fatty acids containing 150 and $300 \mathrm{mg}$ fatty acids were added $5^{-10}$ min after the addition of food. An equal volume of water was added to the control vessel.

The results of one such experiment are shown in Figs. 3 and 4. The amounts of total gas produced in each vessel are shown in Fig. 3. The increases in the volume are expressed arbitrarily in $\mathrm{cm}$ of $\mathrm{H}_{2} \mathrm{O}$ but the volume could be readily obtained by multiplying by a factor of 2.7 (the cross-sectional area of the manometers being $2.7 \mathrm{~cm}^{2}$ ). The curve for the control experiment was characteristic of several similar experiments with sugar-beet pulp where the initial linear increase in total gas changed quite abruptly after $\mathrm{I} \cdot 5 \mathrm{~h}$ or so to a slower but also linear increase. The addition of $150 \mathrm{mg}$ of linseed oil fatty acids to the mixture resulted in a similar curve, which deviated only slightly in a seemingly haphazard manner from the control curve. This deviation was initially attributed to experimental error but, in view of the results obtained when $300 \mathrm{mg}$ of fatty acids were added, the changes could be significant. The initial inhibition of gas production by linseed oil fatty acids was later reversed so that the final volume of gas formed was significantly greater than the volume obtained with no additions. Fig. 3 shows also the negligible increases in gas volume that occurred when the rumen liquor inoculum was replaced by water.

The concentrations of soluble sugar throughout the incubations with sugar-beet pulp are shown in Fig. 4. When no rumen liquor was added, most of the sugar in the sugar-beet pulp dissolved rapidly, but a small amount of it dissolved more slowly. When the rumen liquor was present the fermentation of soluble sugar became rapid even before it was all extracted from sugar-beet pulp. When $300 \mathrm{mg}$ of linseed oil fatty acids were added the rate of disappearance of sugar was reduced at first. Comparison of these results with those given in Fig. 3 indicated that there was good 
correlation between the amount of gas produced and the amount of soluble sugar utilized except for greater total volume of gas when $300 \mathrm{mg}$ of linseed oil fatty acids were given. Moreover, it is clear that the initial fast rate of production of gas was associated with the digestion of the more readily dissolved portion of the carbohydrate of the pulp.

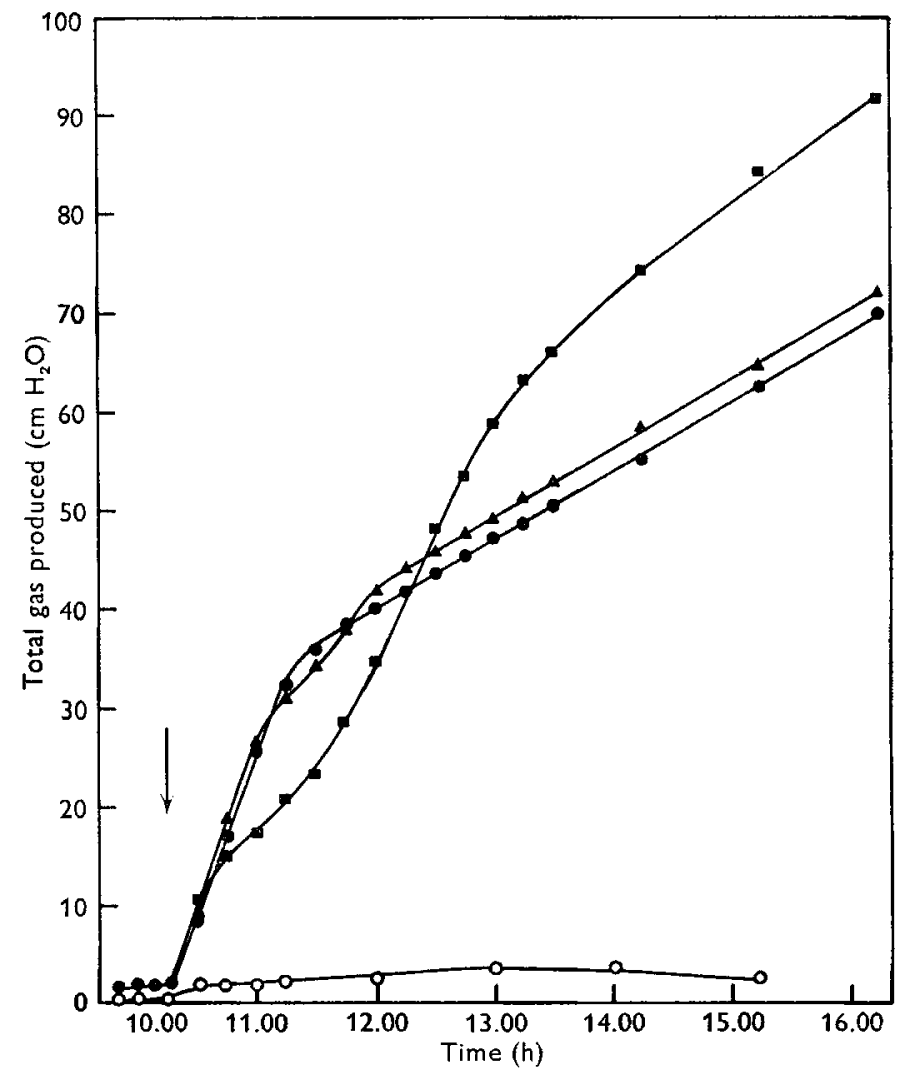

Fig. 3. Total gas production during fermentation of sugar-beet pulp. Each vessel contained $200 \mathrm{ml}$ artificial saliva, $300 \mathrm{ml}$ water and $100 \mathrm{ml}$ strained rumen contents. Sugar-beet pulp ( $5 \mathrm{~g}$ mixed with $5 \mathrm{~g}$ of water) was added at $10.15 \mathrm{~h}$. $\mathrm{O}-\mathrm{O}$, blank incubation-no rumen liquor; - control experiment; $\Delta-\Delta$, I $50 \mathrm{mg}$ of linseed oil acids ( $5 \mathrm{ml}$, half-neutralized with $\mathrm{NaOH}$ solution) added ro min after addition of food; $\square-\square, 300 \mathrm{mg}$ of linseed oil acids added ro min after addition of food.

The concentration of total steam-volatile acids increased approximately linearly, the mean rates being $\mathrm{r} \cdot 7, \mathrm{r} \cdot 8$ and $\mathrm{r} \cdot 3 \mathrm{~m}$-equiv./ $\mathrm{h}$ for the control vessel and the vessels receiving $\mathrm{I} 5{ }^{\circ}$ and $300 \mathrm{mg}$ of linseed oil acids respectively. Some of the samples were analysed to determine the relative concentrations of the volatile acids. In general the ratio of acetic to propionic acid tended to decrease with time in all incubations. In this respect, the fermentation in vitro was analogous to fermentation in the rumen (Table I). However, the changes in vivo were more pronounced than those in vitro. Comparison of results from the control incubation with those in which linseed oil 
fatty acids were added showed that there was a tendency for the ratio of acetic to propionic acid to decrease to a greater extent in the presence of the fatty acids.

The accumulation of steam-volatile acids caused a small decrease in the $\mathrm{pH}$ of the reaction mixtures. The initial $\mathrm{pH}$ was $7.5 \circ$ and, in most instances, it declined linearly at about $0.06 \mathrm{pH}$ units/h.

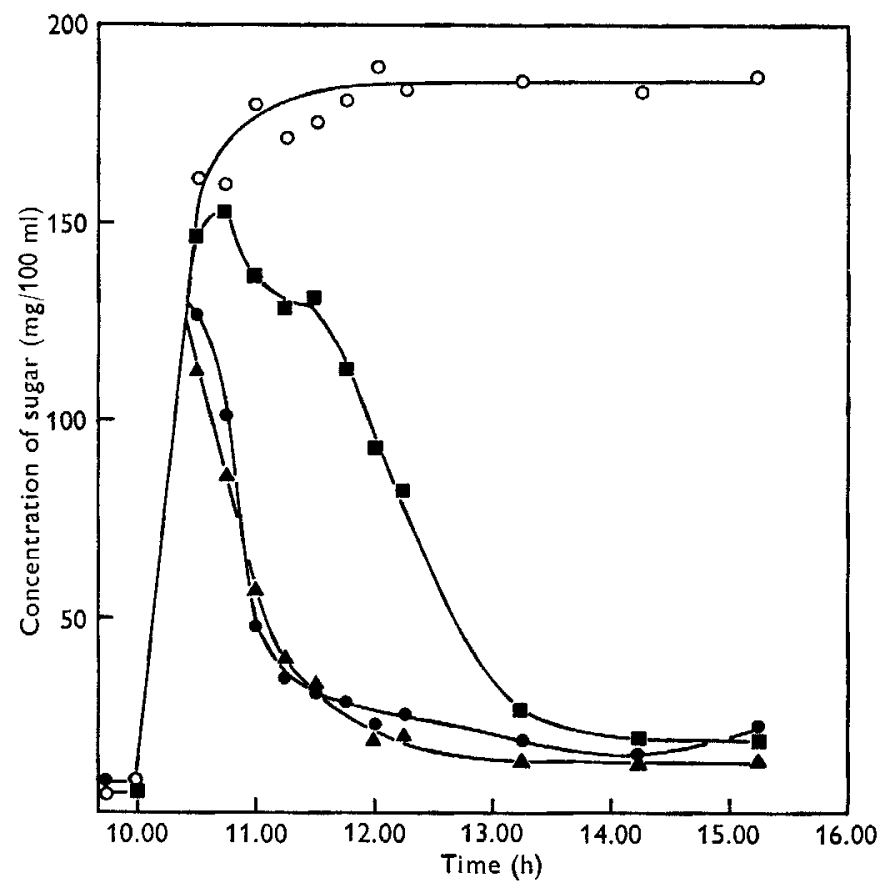

Fig. 4. Concentrations of sugar during incubation of sugar-beet pulp with rumen contents. Full details are given in the legend of Fig. 3. $\mathrm{O}-\mathrm{O}$, blank-no rumen liquor; -0 , control; $\Delta-\Delta, 150 \mathrm{mg}$ linseed oil acids added; $-300 \mathrm{mg}$ linseed oil acids added.

The amounts of methane and hydrogen produced are shown in Table 2. Only the results of analyses of gas samples taken 2 and $6 \mathrm{~h}$ after the addition of sugar-beet pulp are given. Both methane and hydrogen were produced, but when no long-chain fatty acids were added the total amount of hydrogen tended to decrease eventually, although the methane continued to increase. 'This occurred quite consistently when sugar-beet pulp was the substrate (cf. results in vivo, Czerkawski \& Clapperton, r968). Addition of linseed oil acids led to the inhibition of methane production and to increases in the production of hydrogen. The apparently low amount of hydrogen produced after $2 \mathrm{~h}$ when $300 \mathrm{mg}$ of acids were added was due to the relatively small extent of overall fermentation at that time. Analyses of several such results revealed no stoichiometry between the depression of methanogenesis and the accumulation of hydrogen. It was shown above that moderate amounts of the linseed oil acids did not seriously affect the total gas production and the production of steam-volatile acids, yet they produced considerable inhibition of methane production. 


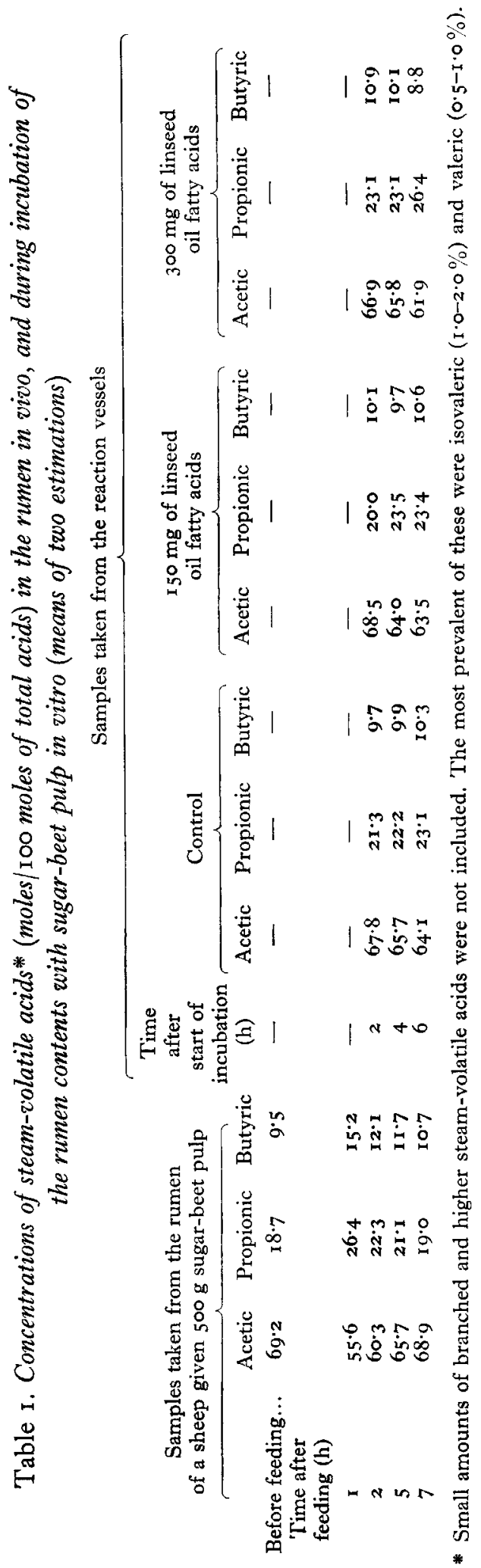


Table 2. Amounts of methane and hydrogen produced (m-moles/vessel) during the fermentation of sugar-beet pulp and of sucrose in vitro

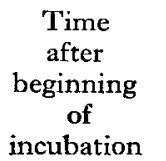

Control, no additions

I $50 \mathrm{mg}$ linseed oil fatty acids

$300 \mathrm{mg}$ linseed oil fatty acids

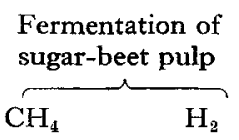

(h)

2

I. 60

$3 \cdot 10$

0.37

0.55

0.35

0.41
$I \cdot 50$

$I \cdot 20$

$2 \cdot 46$

$3 \cdot 60$

0.98

$3 \cdot 91$

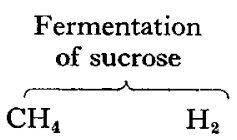

- $\quad-$

$2.26 \quad 0.02$

- 56 -

0.16

$0.46 \quad 0.08$

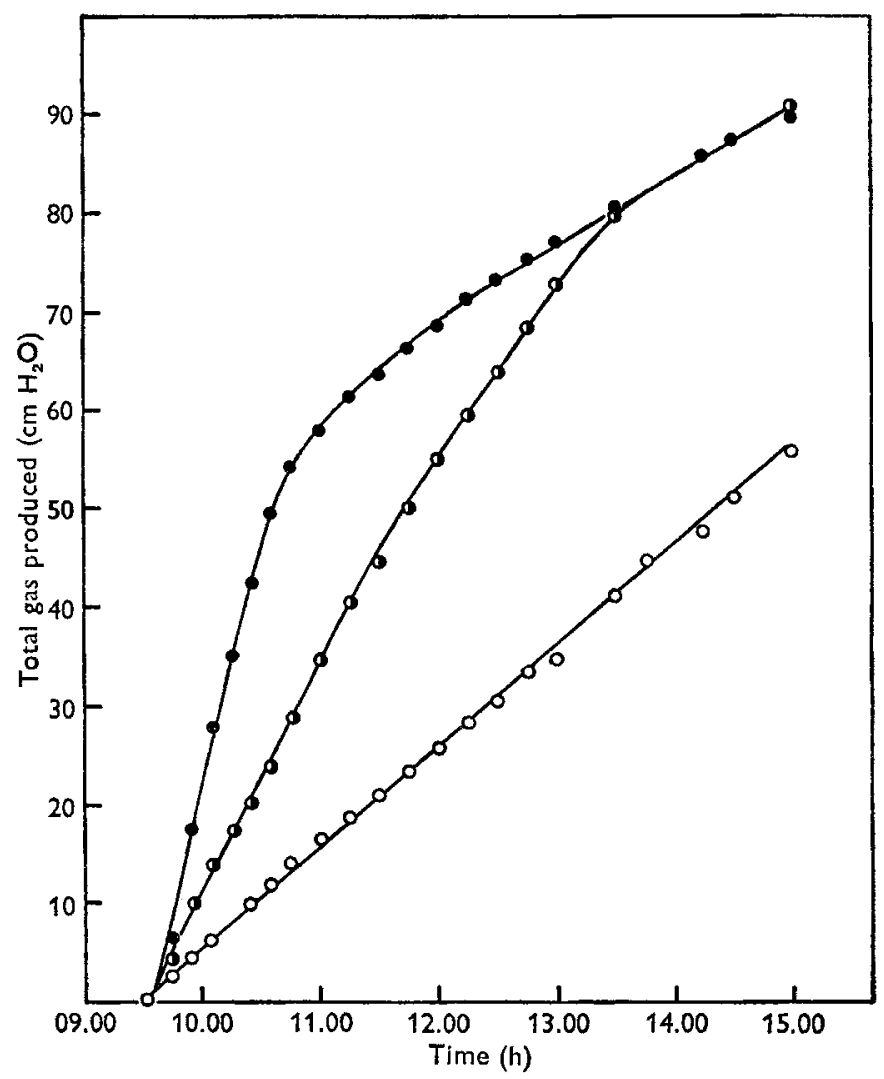

Fig. 5. Effect of the size of inoculum of strained rumen contents on the total gas produced during fermentation of sucrose. Each vessel contained $200 \mathrm{ml}$ buffer solution, $\mathrm{r} \cdot 5 \mathrm{~g}$ sucrose and $0.2 \mathrm{~g}$ ammonium carbonate, rumen liquor and water to give the total volume of $500 \mathrm{ml}$. $\mathrm{O}-\mathrm{O}, 50 \mathrm{ml}$ rumen liquor; $\mathrm{O}-\mathrm{O}, 100 \mathrm{ml}$ rumen liquor; $-0,200 \mathrm{ml}$ rumen liquor.

\section{Fermentation of sucrose}

In order to supply a source of nitrogen with the simple substrate sucrose, two substances were considered, urea and $\left(\mathrm{NH}_{4}\right)_{2} \mathrm{CO}_{3}$. It was decided not to use urea 
because it resulted in an initial lag in gas production. Further exploratory experiments also showed that when no carbohydrate was added urea $(0.5 \mathrm{~g})$ resulted in a steady decrease in the amount of gas produced. This was small, but not negligible $(8-10 \mathrm{~cm}$ $\mathrm{H}_{2} \mathrm{O}$ after $6 \mathrm{~h}$ of incubation), and it accounted for the initial lag in gas production when sucrose was also present.

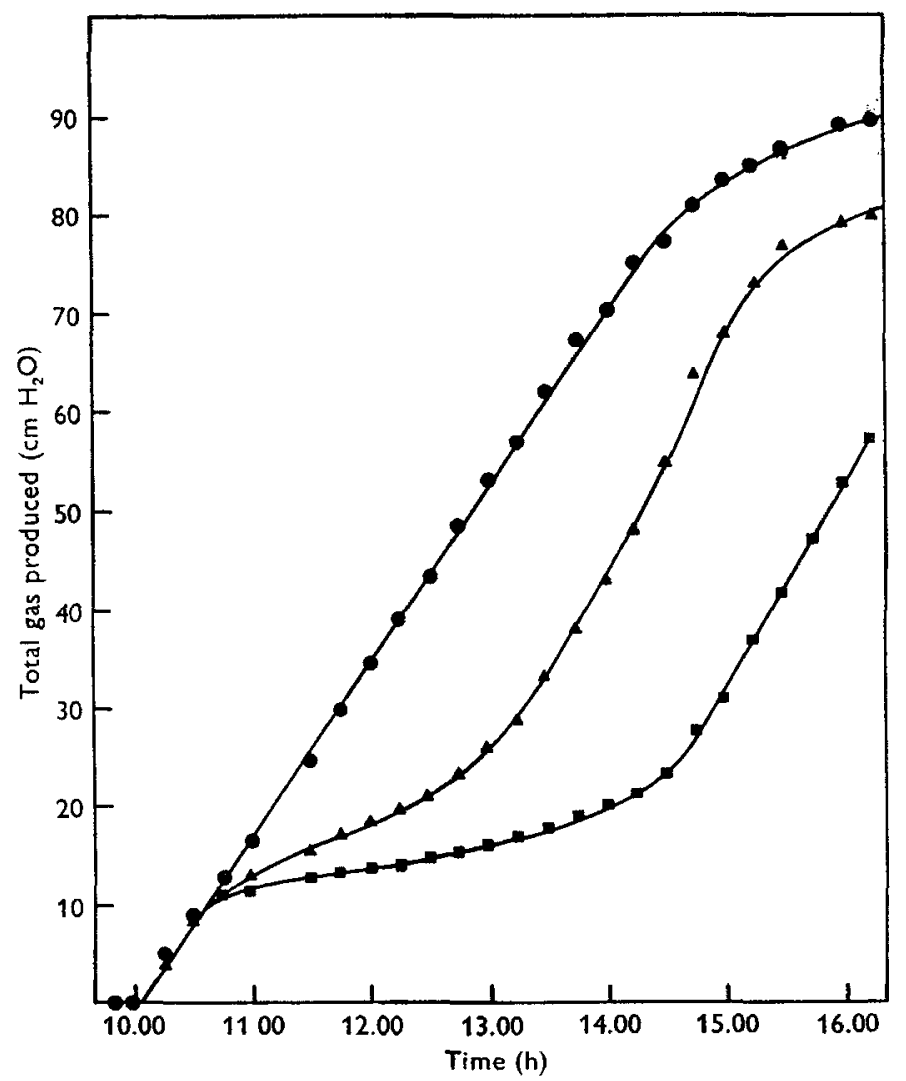

Fig. 6. Effect of linseed oil acids on the total gas production during fermentation of sucrose by rumen micro-organisms. Each vessel contained $200 \mathrm{ml}$ buffer solution, $200 \mathrm{ml}$ water and $100 \mathrm{ml}$ of rumen liquor. Solutions of sucrose $(\mathrm{I} \cdot 5 \mathrm{~g})$ and ammonium carbonate $(0 \cdot 2 \mathrm{~g})$ in $5 \mathrm{ml}$ were added at $10.00 \mathrm{~h}$ and the emulsions of linseed oil acid were added $15 \mathrm{~min}$ later. control - no linseed oil acids added; $\Delta-\Delta, 150 \mathrm{mg}$ linseed oil acids added; $\mathbf{-}-\mathbf{\square}, 300 \mathrm{mg}$ linseed oil acids added.

An addition of $\left(\mathrm{NH}_{4}\right)_{2} \mathrm{CO}_{3}(0 \cdot 2 \mathrm{~g})$ with sucrose $(\mathrm{I} \cdot 5 \mathrm{~g})$ to each vessel resulted in no complications, and these amounts were used in subsequent experiments. The molassed sugar-beet pulp contained $30 \%$ of carbohydrate that was soluble in hot water; therefore, it seemed that $\mathrm{r} \cdot 5 \mathrm{~g}$ of sucrose would be roughly equivalent to $5 \mathrm{~g}$ of the sugarbeet pulp. Preliminary trials indicated that this amount of sucrose was suitable as long as the inoculum of mixed rumen micro-organisms was not too large. The results of some of these experiments are shown in Fig. 5. Thus, although the rate of total gas production remained constant throughout the whole period of incubation of $5.5 \mathrm{~h}$ 
when $50 \mathrm{ml}$ inoculum were used, and tended to fall off slightly when $100 \mathrm{ml}$ were used, to avoid too much dilution of the rumen liquor it became necessary to use the larger inoculum, particularly when the linseed oil acids were added to the reaction mixtures. It can be seen from Fig. 5 that in the first hour or so the rates of production of gas were almost exactly proportional to the size of the inoculum. The same was true for the initial rate of formation of end-products such as carbon dioxide, methane and steam-volatile acids. For example, the initial rates of production of methane when 50,100 and $200 \mathrm{ml}$ of rumen liquor were used were $5.4, \mathrm{II} \cdot \mathrm{I}$ and $2 \mathrm{I}^{\circ} \mathrm{\circ} \mathrm{ml} / \mathrm{h}$ respectively.

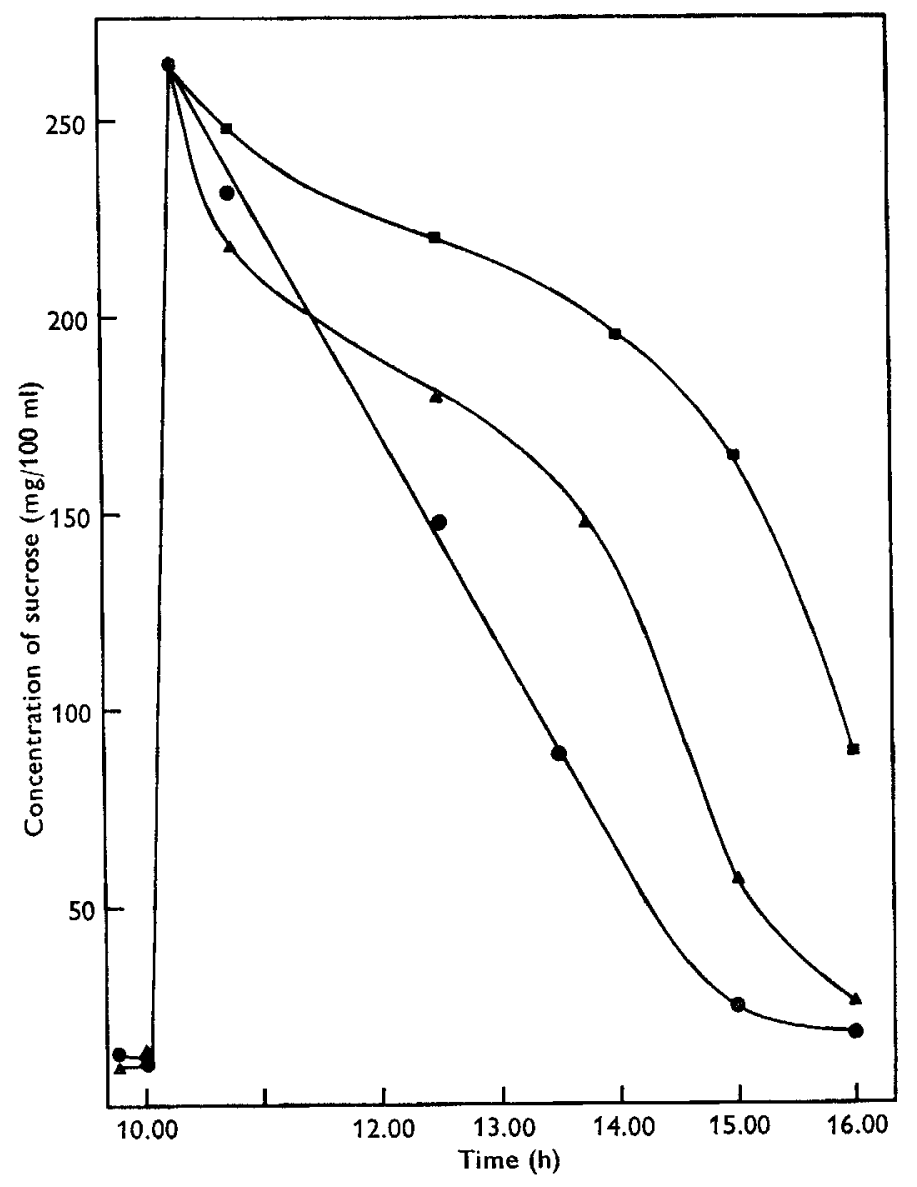

Fig. 7. Effect of linseed oil acids on the fermentation of sucrose by rumen micro-organisms. Full details are given in the legend of Fig. 6. - - control-no linseed oil acids added; $\Delta-\Delta, 150 \mathrm{mg}$ linseed oil acids;

The results of the analysis from one experiment when linseed oil acids were added to the incubation mixture are given in Figs. 6 and 7 . Each vessel contained $300 \mathrm{ml}$ of water, $200 \mathrm{ml}$ artificial saliva and $100 \mathrm{ml}$ of strained rumen liquor. At $10.00 \mathrm{~h}, 5 \mathrm{ml}$

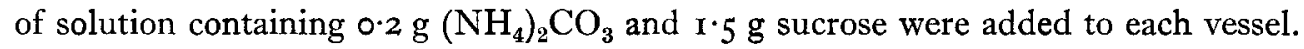


The emulsions of linseed oil fatty acids were added to the second and third vessels ( $15^{\circ}$ and $300 \mathrm{mg}$ fatty acids respectively) at $10.15 \mathrm{~h}$. All the additions were made through the liquid sampling ports.

The values for total gas production are shown in Fig. 6. The control experiment, when no fatty acids were added, resulted in an almost linear increase in the gas production. In this it resembled the fermentation of sugar-beet pulp. However, the time during which gas production was linear was much greater than that obtained with sugar-beet pulp (cf. Fig. 3). Again, addition of linseed oil fatty acids produced a lag and subsequent recovery of the initial rate.

The amounts of soluble sugar in the reaction mixtures are shown in Fig. 7. There was a highly significant correlation $(r=+0.987)$ between the amounts of sugar utilized and the total volumes of gas produced.

The analysis of gas at the end of the experiment again indicated that there was considerable inhibition of methane production (Table 2). There was a small accumulation of hydrogen when methanogenesis was inhibited. However, during the control experiment and also during experiments in which the unsaturated acids were added, the accumulation of hydrogen was smaller than that observed during fermentation of sugar-beet pulp.

\section{DISCUSSION}

Several different types of experiment have already been performed with the apparatus described in this paper, but only two types have been described here. The apparatus consists basically of parts that can be obtained commercially and, which is important, can be easily modified to meet specific requirements. Although, theoretically, it would be possible to do four to five concurrent experiments every day, in practice, because of the necessary preparations and subsequent analyses, we have been limited to 2 days per week. Nevertheless, this means eight to ten screening trials per week.

The experiments with sugar-beet pulp showed that, during the short-term experiments, the fermentation pattern was similar to the one that occurs in vivo. The initial fast rate of gas production was consistent with the rapid rates of methane production that occur in vivo (Clapperton \& Czerkawski, 1967). The soluble sugar of the diet was metabolized rapidly, and in fact the rate of its removal was often greater than the rate at which it dissolved from sugar-beet pulp. A similar situation exists in vivo where the rate of utilization of soluble sugar after giving sugar-beet pulp to sheep exceeds the rate at which it is dissolved. The concentration of sugar in the rumen rises to about a quarter of the maximum value calculated from the sugar content of the ration, and even this rise is limited to a short time after feeding. Within $2 \mathrm{~h}$ the concentrations of these sugars fall to almost the values observed before feeding. Essentially similar gas production curves were observed when sucrose was supplemented with ammonium salts. The total amounts of sucrose used $(\mathrm{I} \cdot 5 \mathrm{~g})$ were calculated to be approximately equivalent to the soluble sugar in $5 \mathrm{~g}$ of sugar-beet pulp. However, with sucrose the fast rate of gas production lasts longer and the rate of methane production is less than with sugar-beet pulp (cf. Figs. 3, 5, 6 and Table 2). 
This presumably is due to the fact that sugar-beet pulp contains a complex mixture of substances.

The linseed oil fatty acids were an efficient inhibitor of methanogenesis, whether the sugar-beet pulp or sucrose was used. This agrees well with the results of experiments with sheep (Czerkawski et al. I 966; Czerkawski, I966). In these experiments, between $\mathrm{I} 5$ and $3 \circ \mathrm{g}$ of the long-chain acids were incorporated with each meal. If it is assumed that the volume of the rumen contents of a sheep is 71 ., the final concentration of these acids would be $215-430 \mathrm{mg} / 100 \mathrm{ml}$ rumen contents. In the present experiments although $150 \mathrm{mg}$ of the acids produced considerable inhibition of methane production, they had little effect on the general fermentation pattern of sugar-beet pulp, as judged by the rate of utilization of sugar or the rates of production of steamvolatile acids.

The fermentation of sucrose appeared to be more susceptible to the linseed oil acids than the fermentation of sugar-beet pulp. However, other experiments, not reported here, indicated that when $80 \mathrm{mg}$ of acids were added when sucrose was the substrate the fermentation pattern was not affected, except for the inhibition of methanogenesis and a slight rise in hydrogen production. It was shown by Ullyat \& Czerkawski (unpublished results) that, when linseed oil acids are infused into the rumen of sheep, the long-chain acids are almost wholly adsorbed on to particles of digesta, and presumably the discrepancy between the two types of results reported here can be explained by a certain measure of protection offered by the solid food particles. This might also explain why, during experiments with sheep, much larger amounts of acids could be administered without affecting the digestibility of the ration (Czerkawski et al. 1966).

Although the administration of large amounts of linseed oil acids caused an initial inhibition of gas production and of sugar utilization, in most experiments this inhibition was temporary, and after a time lag that depended directly on the amounts of acids used, the rates of gas production recovered and reached the control value. When sucrose was used the final rates of gas production and the final levels of gas produced were the same whether the fatty acids were added or not. When sugar-beet pulp was the substrate the amounts of gas finally produced after the initial inhibition were invariably larger than the control values. No explanation of this observation can be offered at this stage.

We are grateful to Drs J. H. Moore and C. G. Harfoot for many helpful discussions and for constructive criticism, to Mrs C. Faulds for extensive analytical assistance and to $\mathrm{Mr} \mathrm{J}$. Henderson for construction of the expansion chambers.

\section{REFERENCES}

Alexander, R. H. \& McGowan, M. (I966). F. Br. Grassld Soc. 21, I40.

Clapperton, J. L. \& Czerkawski, J. W. (1967). Proc. Nutr. Soc. 26, xxi.

Conway, E. J. (1 962). Microdiffusion Analysis and Volumetric Error, p. 234. London: Crosby, Lockwood and Son Ltd.

Czerkawski, J. W. (1966). Br. Y. Nutr. 2o, 833 .

Czerkawski, J. W. (1967). Br. F. Nutr. 21, 865 . 
Czerkawski, J. W., Blaxter, K. L. \& Wainman, F. W. (r966). Br. F. Nutr. 20, 485 .

Czerkawski, J. W. \& Clapperton, J. L. (I 968). Lab. Pract. 17, 994.

Dawson, R. M. C., Ward, P. F. V. \& Scott, T. W. (I 964). Biochem. F. 9o, 9.

Hobson, P. N. (1965). F. gen. Microbiol, 38, 16ı.

James, A. T. \& Martin, A. J. P. (1952). Biochem. F. 50, 679.

Marston, H. R. (1948). Biochem. F. 42, 564.

McDougall, E. I. (1948). Biochem. Y. 43, 99.

Slyter, L. L. \& Putnam, P. A. (1967). F. Anim. Sci. 26, г421.

Smith, F. (1 956). Meth. biochem. Analysis 3, 180.

Warner, A. C. I. (1956). F. gen. Microbiol. 14, 733.

EXPLANATION OF PLATE

Pl. I. General view of the artificial rumen. 
British Fournal of Nutrition, Vol. 23, No. I

Plate I

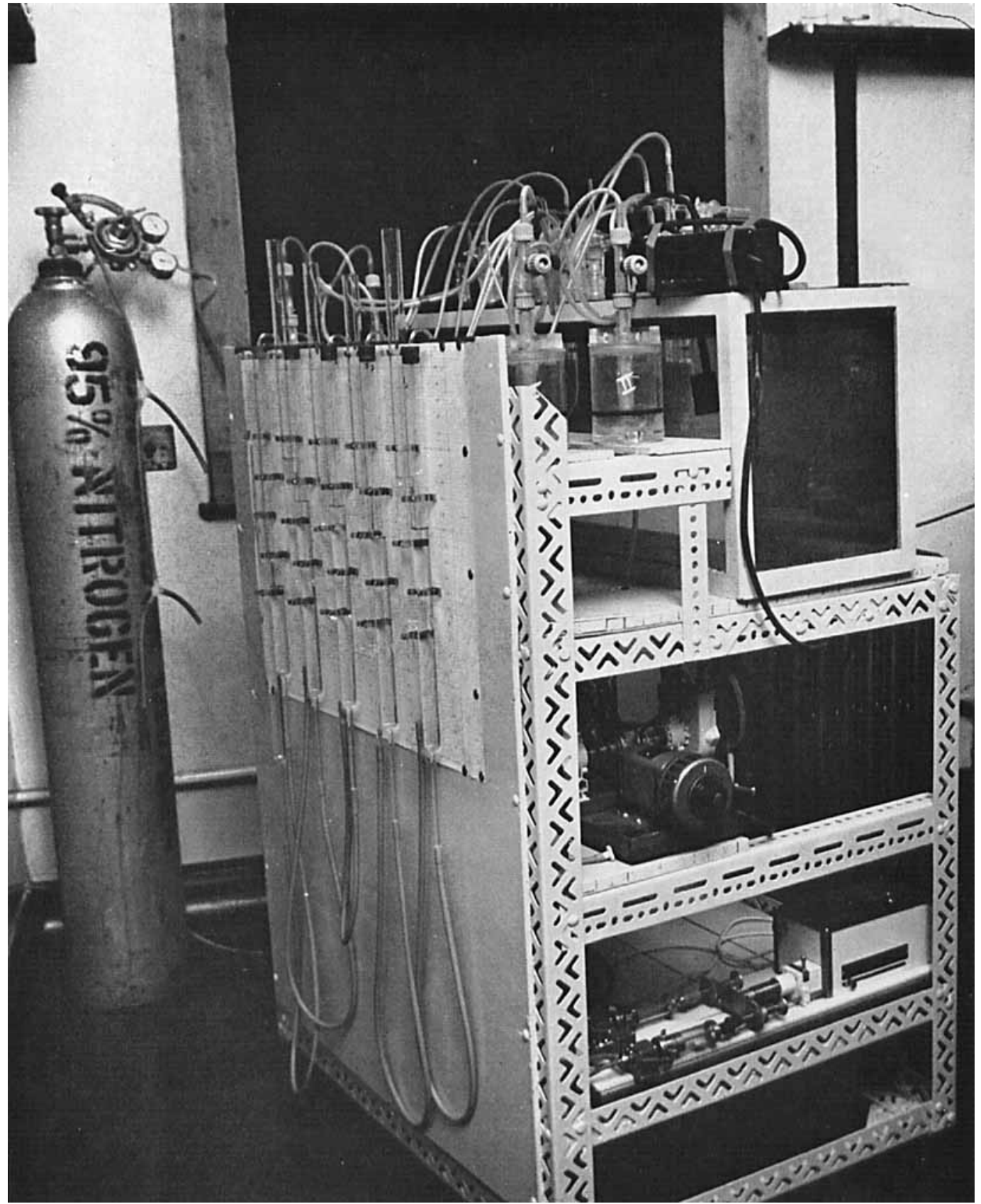

